\title{
Food hardness and stone tool weight in wild primate nut-cracking
}

Michael Haslam ${ }^{1 *}$

${ }^{1}$ School of Archaeology, University of Oxford, Oxford OX1 3QY, UK

*Corresponding author email: mahaslam@gmail.com

ORCID: 0000-0001-8234-7806

\section{Abstract}

This study presents data on average stone tool weights and the hardness of foods processed by the three known stone-tool-using primate species: Burmese long-tailed macaques (Macaca fascicularis aurea), bearded capuchins (Sapajus libidinosus) and Western chimpanzees (Pan troglodytes verus). Each of these primates uses stone hammers to crack open nuts in the wild, making them suitable for inter-species behavioural comparison. This work draws on published results to identify a distinct difference in the tool weight/food hardness curve between chimpanzees and the two monkey taxa, with the latter reaching an asymptote in mean tool weight of just over $1 \mathrm{~kg}$ regardless of increasing food hardness. In contrast, chimpanzees rapidly increase their tool weight in response to increasing hardness, selecting average masses over $5 \mathrm{~kg}$ to process the hardest nuts. Species overlap in their preference for tools of $0.8-1 \mathrm{~kg}$ for opening foods of hardness $2-3 \mathrm{kN}$, suggesting that this conjunction may represent a primate stone-tool-use optimum.

\section{Keywords}

Stone tool; percussion; hammer; macaque; capuchin; chimpanzee 


\section{Introduction}

Stone tools have been an essential component of the hominin (human lineage) toolkit for millions of years (Harmand et al. 2015). Until the late twentieth century, however, our primary reference for the use of such tools was other hominins, including modern humans (Reybrouck 2012). With the discovery that some members of the West African chimpanzee sub-species (Pan troglodytes verus) used stones to break open nuts in the wild, direct comparison with the behaviour of these living apes became feasible (Joulian 1996; Marchant and McGrew 2005; Whiten et al. 2009; Boesch 2012). Subsequently, bearded capuchin monkeys (Sapajus libidinosus) in Brazil (Ottoni and Izar 2008; Proffitt et al. 2016) and Burmese long-tailed macaques (Macaca fascicularis aurea) in Thailand (Gumert and Malaivijitnond 2012; Haslam et al. 2016b) were also found to use stone pounding tools in their natural habitats. However, despite the fact that the two monkeys are equally as phylogenetically related to modern chimpanzees as they are to modern humans, hominin comparisons still dominate discussions of this behaviour (Visalberghi et al. 2015; Falótico et al. 2017).

Here, I compare the one type of stone tool use known to be shared by these three nonhuman primates (hereafter, primates): nut-cracking. Specifically, I examine how the hardness of a processed food influences the selected weight of stone pounding tools. These two variables have been shown to be significantly correlated in single-species studies (Boesch and Boesch 1983; Spagnoletti et al. 2011; Gumert and Malaivijitnond 2013), however they have not previously been assessed in an inter-species study. 
In-depth coverage of the sites and types of wild stone tool use in these primates may be found elsewhere (Gumert et al. 2009; Matsuzawa 2011; Boesch 2012; Visalberghi and Fragaszy 2013; Falótico and Ottoni 2016). In summary, bearded capuchins commonly use handheld stones to pound open encased nuts, including palm nuts (Attalea, Astrocarpum and Orbignya) and cashews (Anacardium sp.) (Visalberghi and Fragaszy 2013; Mendes et al. 2015; Luncz et al. 2016b). Burmese long-tailed macaques primarily use handheld stones to process intertidal oysters and gastropods (Gumert and Malaivijitnond 2012), however they have also been observed to pound open nuts of sea almonds (Terminalia catappa) (Falótico et al. 2017) and oil palms (Elaeis guineensis) (Luncz et al. 2017). Chimpanzees stone tool use is focused on cracking a variety of nuts and fruits (including Panda, Coula, Parinari and Elaeis) (McGrew 1992). All three primates select and transport stones to tool-use sites, for use as hammers (Visalberghi et al. 2013; Haslam et al. 2016b; Luncz et al. 2016a) and anvils (Sakura and Matsuzawa 1991; Haslam et al. 2016a).

\section{Methods}

I collated available published data on wild primate activities that involve use of a handheld hammerstone to break open encased food, where both tool weights and the food hardness are available. With one exception (see below), I only included behaviour recorded in natural settings, rather than from captive or experimental situations (Matsuzawa 1994; Visalberghi et al. 2009; Luncz et al. 2016b), in order to avoid biases that humans may introduce to primate performance (Haslam 2013). Data were drawn from the literature, except for the average weight of tools $(n=348)$ used by wild macaques to process oil palm nuts on Koh Yao Noi, Thailand. The latter data were recorded during surveys in October 2016 as part of the ERC-funded Primate Archaeology project. 
To ensure comparability, I included only measures of food hardness expressed as fracture force (in $\mathrm{kN}$ ). This variable is the one most relevant to primate stone pounding behaviour, as opposed to food toughness, for example (Berthaume 2016). I used average tool weights, combined for both sexes, because researchers rarely provided raw data that would permit more precise comparisons. Tool data were only included when the report indicated that a single species of nut was processed with those tools. For the purposes of this initial report, I have not taken tool hardness or material into account, although I acknowledge that these factors will affect the effectiveness of a stone hammer of a given weight.

Tool weights from the capuchin Fazenda Boa Vista (FBV) site have been reported in terms of their use on 'high resistance' and 'low resistance' nuts (Spagnoletti et al. 2011), and I have followed that procedure here, leading to identical weights for tools used to process each of the nut species that fall into these categories (see Table 1). Chimpanzee tools from the Taï Forest have been published in weight categories (Boesch and Boesch 1984; Luncz et al. 2016a), and an average value was therefore calculated by assigning each category a weight in the centre of its range (e.g., the category '1-2.9 kg' was assigned a value of $2 \mathrm{~kg}$ ) (Boesch and Boesch 1984). The macaque data include the two nut species processed with stone tools; however, I also included two gastropod species to reflect the fact that these monkeys predominantly use stones on shellfish. The gastropods include relatively easily-opened (Nerita sp.) and hard-shelled (Thais sp.) prey. The macaque shell-cracking data are the exception to my excluding experimentally provided stones (Gumert and Malaivijitnond 2013), as mollusc-specific tool weights are not otherwise available. 


\section{Results and Discussion}

Results are presented in Table 1 and Fig. 1. The results replicate previous findings that tool selection, in terms of average weight, is positively correlated with food hardness for all three non-human primate stone-tool-using species. However, the inter-species comparison reveals that this is not a linear process. Instead, each of the primates asymptotically approaches a maximum average tool weight, where increasing food hardness results in successively smaller increases in selected tool weight.

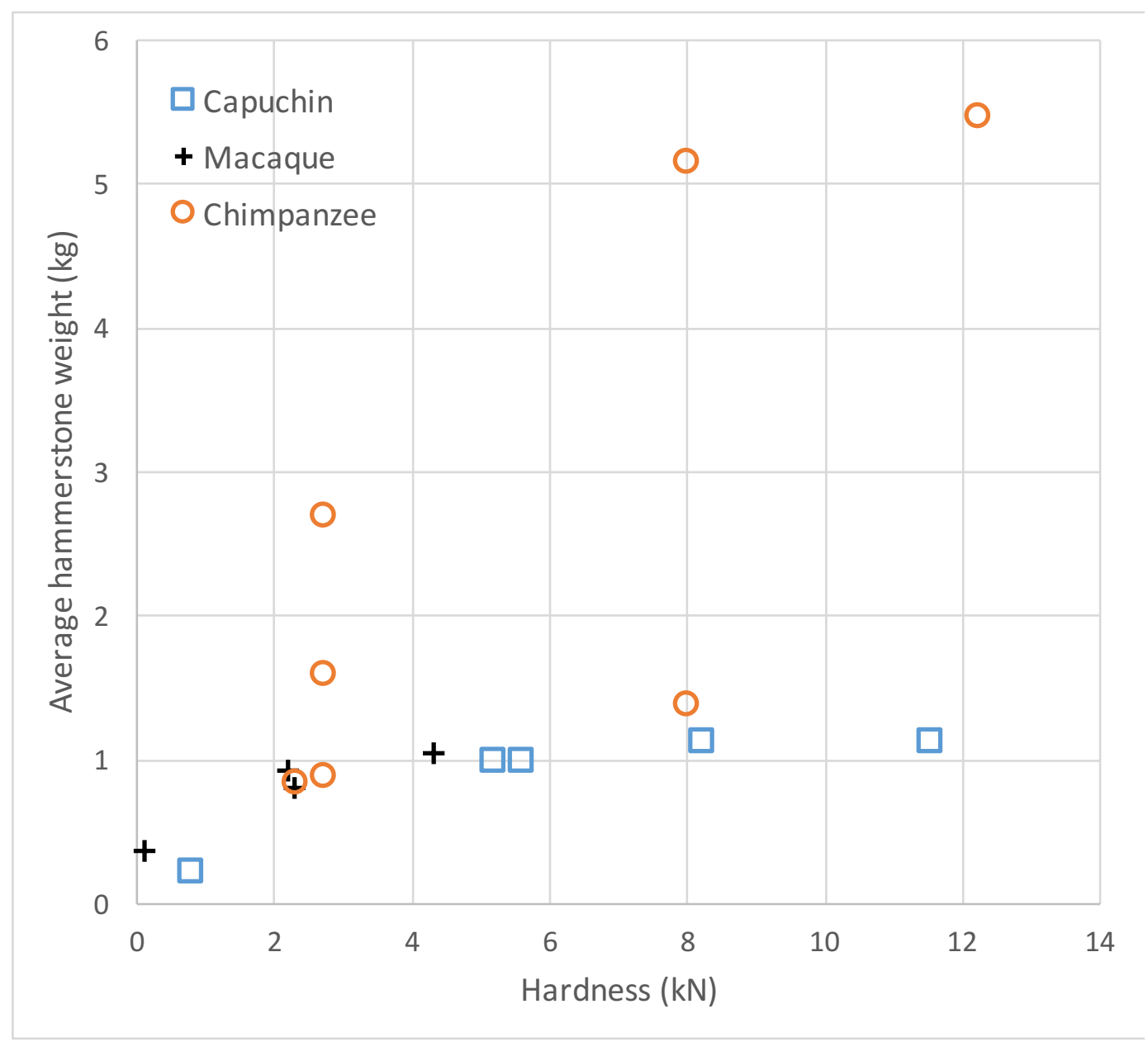

Fig. 1 Food hardness $(\mathrm{kN})$ and associated average hammerstone weight $(\mathrm{kg})$ for wild nonhuman primates 
Table 1 Food hardness and associated stone tool weights for wild non-human primates

\begin{tabular}{|c|c|c|c|c|c|}
\hline Primate & Site & Food & Hardness (kN) & $\begin{array}{l}\text { Mean tool } \\
\text { weight (kg) }\end{array}$ & Ref. \\
\hline \multirow{5}{*}{$\begin{array}{l}\text { Sapajus } \\
\text { libidinosus }\end{array}$} & Fazenda Boa Vista, & Attalea barreirensis & 5.15 & 1.049 & \multirow{4}{*}{ (Visalberghi et al. 2008; Spagnoletti 2009) } \\
\hline & Brazil & Astrocarpum campestre & 5.57 & 1.049 & \\
\hline & & Attalea sp. & 8.19 & 1.111 & \\
\hline & & Orbignya sp. & 11.5 & 1.111 & \\
\hline & $\begin{array}{l}\text { Serra da Capivara, } \\
\text { Brazil }\end{array}$ & Anacardium sp. & 0.78 & 0.234 & $\begin{array}{l}\text { (Ogunsina and Bamgboye 2013; Falótico and Ottoni } \\
\text { 2016) }\end{array}$ \\
\hline \multirow{5}{*}{$\begin{array}{l}\text { Macaca } \\
\text { fascicularis } \\
\text { aurea }\end{array}$} & Piak Nam Yai, & Terminalia catappa & 2.19 & 0.923 & \multirow{4}{*}{$\begin{array}{l}\text { (Sterling 1994; Falótico et al. 2017) } \\
\text { (Hughes 1989; Gumert and Malaivijitnond 2013) } \\
\text { (Vermeij and Currey 1980; Gumert and } \\
\text { Malaivijitnond 2013) }\end{array}$} \\
\hline & Thailand & Nerita sp. & 0.1 & 0.363 & \\
\hline & & Thais sp. & 4.3 & 1.045 & \\
\hline & & & & & \\
\hline & $\begin{array}{l}\text { Koh Yao Noi, } \\
\text { Thailand }\end{array}$ & Elaeis guineensis & 2.3 & 0.425 & (Owolarafe et al. 2007) \\
\hline \multirow{7}{*}{$\begin{array}{l}\text { Pan } \\
\text { troglodytes } \\
\text { verus }\end{array}$} & Bossou, Guinea & Elaeis guineensis & 2.3 & 0.849 & (Humle and Matsuzawa 2004; Owolarafe et al. 2007) \\
\hline & Mt Kantan, Liberia & Coula edulis & 2.72 & 0.89 & (Kortlandt and Holzhaus 1987; Peters 1987) \\
\hline & Sapo, Liberia & Coula edulis & 2.72 & 1.6 & \multirow{2}{*}{ (Anderson et al. 1983; Peters 1987) } \\
\hline & & Parinari excelsa & 7.98 & 1.4 & \\
\hline & Taï Forest, Ivory & Panda oleosa & 12.21 & 5.488 & \multirow{2}{*}{ (Boesch and Boesch 1984; Peters 1987) } \\
\hline & Coast & Coula edulis & 2.72 & 2.7 & \\
\hline & & Parinari excelsa & 7.98 & 5.167 & (Boesch and Boesch 1983; Peters 1987) \\
\hline
\end{tabular}


The two monkey species follow approximately the same shallow curve, with each using lighter tools to process softer materials (Nerita for macaques, cashews for capuchins), and reaching a maximum average of just over a kilogram for tools used on the hardest capuchin palm nuts and macaque molluscs. Heavier stones suitable for use as hammers are available, albeit not abundant, at all the well-studied monkey tool-use sites ( $\mathrm{MH}$, pers. obs.), which suggests that stone availability is not solely dictating this asymptote. Instead, the limiting factor may be body size and associated strength in manipulating stones. Supporting this suggestion, female capuchins at FBV used significantly lighter hammerstones when cracking low resistance as opposed to high resistance nuts, whereas the larger males showed no such distinction (Spagnoletti et al. 2011). Similarly, male macaques on Piak Nam Yai used heavier stones significantly more often than did the smaller females (Gumert et al. 2011). However, long-tailed macaques typically weigh 4-7 kg (Hamada et al. 2008) and bearded capuchins 2$4 \mathrm{~kg}$ (Fragaszy et al. 2016), and if body size is an important determinant of tool size (Visalberghi et al. 2015), then we may expect the macaque curve to level out above that of the capuchins. Testing this hypothesis will require finding wild M.f. aurea populations that have naturally developed stone tool use on harder foods than those currently processed.

The chimpanzee curve rises much faster than that of either of the monkeys, beginning to level out only above $5 \mathrm{~kg}$ tool weight, and not yet reaching a clear asymptote. Given that foods of similar hardness are cracked by both chimpanzees and capuchins (for example, Panda and Orbignya), the stark discrepancy between these two taxa is again most likely explained by differences in strength derived from body weight. Adult Western chimpanzees can weigh approximately $45-55 \mathrm{~kg}$, and the wild capuchins therefore need to use stones that weigh a significantly higher proportion of their body mass to break open highly resistant 
nuts (Visalberghi et al. 2015). Complicating this picture slightly, one chimpanzee data point for processing Parinari at Sapo in Liberia - falls closer to the monkey curves, indicating that there is likely more variation to be uncovered as additional food-specific tool choices are recorded under natural conditions. In any case, the data suggest that wild stone-tool-using chimpanzees are capable of cracking open items of higher maximum hardness than has been recorded to date. Whether foods or other objects of such hardness exist in their habitats, and whether the chimpanzees would gain from breaking them open, requires further study.

The dominance of average weights in the published literature, and relied upon here, obscures extremes and may bias the current study in unknown ways. For example, chimpanzees in the Taï Forest have been reported to use tools up to $24 \mathrm{~kg}$ (Boesch and Boesch 1983), and capuchins at Fazenda Boa Vista were observed to occasionally use hammers up to $3 \mathrm{~kg}$ (Spagnoletti et al. 2011). Nevertheless, the use of mean weights has the benefit of focusing on common behaviour, not just that of the strongest - typically male individuals. Reporting of more complete datasets in the future will aid in parsing the necessarily broad conclusions drawn in this initial investigation, as will further characterization of the hardness of foods pounded by non-human primates.

The emphasis on averages does permits direct comparisons across all three nut-cracking non-human primates, potentially identifying cross-taxa preferences. For example, the monkey and chimpanzee curves meet at a collection of data points between $2-3 \mathrm{kN}$ and 0.8 $1 \mathrm{~kg}$. On present evidence, this combination of food hardness and tool weight may therefore record something of an inter-species stone tool use optimum for primates. 
Although comparison between extant primate and extinct hominin percussion was not the aim of this study, the inclusion of hominin percussive hammerstone data from sites where pounding activities and consumed foods can be inferred (Arroyo and de la Torre 2016) would act as a test of this suggestion. Finally, if body mass is indeed a driver of tool weight, then hominin stone tool selection would be expected to more closely follow the chimpanzee curve rather than those of the monkeys. Similarly, if additional extant stonetool-using primates are discovered, their percussive preferences will add valuable extra information to the comparative data against which past primate and hominin behavioral reconstructions can be assessed (Haslam et al. 2017).

\section{Acknowledgements}

I thank the members of the Primate Archaeology research network for their advice, and Lydia Luncz, Magda Svensson and Michael Gumert for their assistance in Thailand. This work was funded by a European Research Council Starting Grant (no. 283959) awarded to MH. 


\section{References}

Anderson J, Williamson E, Carter J (1983) Chimpanzees of Sapo Forest, Liberia: density, nests, tools and meat-eating. Primates 24:594-601

Arroyo A, de la Torre I (2016) Assessing the function of pounding tools in the Early Stone Age: a microscopic approach to the analysis of percussive artefacts from Beds I and II, Olduvai Gorge (Tanzania). J Archaeol Sci 74:23-34 . doi: 10.1016/j.jas.2016.08.003 Berthaume MA (2016) Food mechanical properties and dietary ecology. Am J Phys Anthropol 159:S79-S104 . doi: 10.1002/ajpa.22903

Boesch C (2012) Wild cultures: A comparison between chimpanzee and human cultures. Cambridge University Press, Cambridge

Boesch C, Boesch H (1983) Optimization of nut-cracking with natural hammers by wild chimpanzees. Behaviour 83:265-286

Boesch C, Boesch H (1984) Mental map in wild chimpanzees: an analysis of hammer transports for nut cracking. Primates 25:160-170 . doi: 10.1007/BF02382388

Falótico T, Ottoni EB (2016) The manifold use of pounding stone tools by wild capuchin monkeys of Serra da Capivara National Park, Brazil. Behaviour 153:421-442 . doi: $10.1163 / 1568539 X-00003357$

Falótico T, Spagnoletti N, Haslam M, et al (2017) Analysis of sea almond (Terminalia catappa) cracking sites used by wild Burmese long-tailed macaques (Macaca fascicularis aurea). Am J Primatol. doi: 10.1002/ajp.22629

Fragaszy DM, Izar P, Liu Q, et al (2016) Body mass in wild bearded capuchins, (Sapajus libidinosus): ontogeny and sexual dimorphism. Am J Primatol 78:473-484 . doi: 10.1002/ajp.22509

Gumert M, Hoong LK, Malaivijitnond S (2011) Sex differences in the stone tool-use behavior 
of a wild population of Burmese long-tailed macaques (Macaca fascicularis aurea). Am J Primatol 73:1-11

Gumert M, Kluck M, Malaivijitnond S (2009) The physical characteristics and usage patterns of stone axe and pounding hammers used by long-tailed macaques in the Andaman Sea region of Thailand. Am J Primatol 71:594-608

Gumert M, Malaivijitnond S (2012) Marine prey processed with stone tools by Burmese long-tailed macaques (Macaca fascicularis aurea) in intertidal habitats. Am J Phys Anthropol 149:447-457

Gumert MD, Malaivijitnond S (2013) Long-tailed macaques select mass of stone tools according to food type. Philos Trans R Soc B 368:20120413 . doi:

$10.1098 /$ rstb.2012.0413

Hamada Y, Suryobroto B, Goto S, Malaivijitnond S (2008) Morphological and body color variation in Thai Macaca fascicularis fascicularis north and south of the Isthmus of Kra. Int J Primatol 29:1271-1294 . doi: 10.1007/s10764-008-9289-y

Harmand S, Lewis JE, Feibel CS, et al (2015) 3.3-million-year-old stone tools from Lomekwi 3, West Turkana, Kenya. Nature 521:310-315 . doi: 10.1038/nature14464

Haslam M (2013) "Captivity bias" in animal tool use and its implications for the evolution of hominin technology. Philos Trans R Soc B 368:20120421 . doi: 10.1098/rstb.2012.0421 Haslam M, Hernandez-Aguilar RA, Proffitt T, et al (2017) Primate archaeology evolves. Nat Ecol Evol 1:1431-1437 . doi: 10.1038/s41559-017-0286-4

Haslam M, Luncz L V, Staff RA, et al (2016a) Pre-Columbian monkey tools. Curr Biol 26:R521-R522 . doi: 10.1016/j.cub.2016.05.046

Haslam M, Pascual-Garrido A, Malaivijitnond S, Gumert M (2016b) Stone tool transport by wild Burmese long-tailed macaques (Macaca fascicularis aurea). J Archaeol Sci Reports 
7:408-413 . doi: 10.1016/j.jasrep.2016.05.040

Hughes RN (1989) Foraging behaviour of a tropical crab: Ozius verreauxii. Proc R Soc B Biol

Sci 237:201-212 . doi: 10.1098/rspb.1989.0044

Humle T, Matsuzawa T (2004) Oil palm use by adjacent communities of chimpanzees at

Bossou and Nimba Mountains, West Africa. Int J Primatol 25:551-581 . doi:

10.1023/B:IJOP.0000023575.93644.f4

Joulian F (1996) Comparing chimpanzee and early hominid techniques: some contributions

to cultural and cognitive questions. In: Mellars P, Gibson K (eds) Modelling the Early

Human Mind . McDonald Institute for Archaeological Research, Cambridge, pp 173-189

Kortlandt A, Holzhaus E (1987) New data on the use of stone tools by chimpanzees in

Guinea and Liberia. Primates 28:473-496

Luncz L V., Proffitt T, Kulik L, et al (2016a) Distance-decay effect in stone tool transport by wild chimpanzees. Proc R Soc B Biol Sci 283:20161607 . doi: 10.1098/rspb.2016.1607

Luncz L V, Falótico T, Pascual-Garrido A, et al (2016b) Wild capuchin monkeys adjust stone tools according to changing nut properties. Sci Rep 6:33089 . doi: 10.1038/srep33089 Luncz L V, Svensson MS, Haslam M, et al (2017) Technological response of wild macaques (Macaca fascicularis) to anthropogenic change. Int J Primatol 38:872-880 . doi: $10.1007 / \mathrm{s} 10764-017-9985-6$

Marchant LF, McGrew WC (2005) Percussive technology: chimpanzee baobab smashing and the evolutionary modeling of hominid knapping. In: Roux V, Bril B (eds) Stone Knapping: The Necessary Conditions for a Uniquely Hominin Behaviour . McDonald Institute for Archaeological Research, Cambridge, pp 341-350

Matsuzawa T (2011) Stone tools for nut-cracking. In: Matsuzawa T, Humle T, Sugiyama Y (eds) The Chimpanzees of Bossou and Nimba. Springer, Dordrecht, pp 73-83 
Matsuzawa T (1994) Field experiments on the use of stone tools by chimpanzees in the wild.

In: Wrangham R, McGrew WC, de Waal F, Heltne P (eds) Chimpanzee Cultures. Harvard University Press, Cambridge, pp 351-370

McGrew WC (1992) Chimpanzee Material Culture: Implications for Human Evolution.

Cambridge University Press, Cambridge

Mendes FDC, Cardoso RM, Ottoni E, et al (2015) Diversity of nutcracking tool sites used by Sapajus libidinosus in Brazilian cerrado. Am J Primatol 77:535-546 . doi:

10.1002/ajp.22373

Ogunsina B, Bamgboye A (2013) Fracture resistance of cashew nuts as influenced by preshelling treatment. Int J Food Prop 16:1452-1459

Ottoni E, Izar P (2008) Capuchin monkey tool use: overview and implications. Evol Anthropol $17: 171-178$

Owolarafe OK, Olabige MT, Faborode MO (2007) Physical and mechanical properties of two varieties of fresh oil palm fruit. J Food Eng 78:1228-1232 . doi:

10.1016/j.jfoodeng.2005.12.049

Peters CR (1987) Nut-like oil seeds: food for monkeys, chimpanzees, humans, and probably ape-men. Am J Phys Anthropol 73:333-363 . doi: 10.1002/ajpa.1330730306

Proffitt T, Luncz L V, Falótico T, et al (2016) Wild monkeys flake stone tools. Nature 539:8588. doi: 10.1038/nature20112

Reybrouck D Van (2012) From Primitives to Primates: A history of ethnographic and primatological analogies in the study of prehistory. Sidestone Press, Leiden

Sakura O, Matsuzawa T (1991) Flexibility of wild chimpanzee nut-cracking behavior using stone hammers and anvils: an experimental analysis. Ethology 87:237-248 . doi: 10.1111/j.1439-0310.1991.tb00249.x 
Spagnoletti N (2009) Uso di strumenti in una popolazione di Cebus libidinosus allo stato selvatico in Piauí, Brasile. PhD Thesis, Sapienza Università di Roma. Sapienza Università di Roma

Spagnoletti N, Visalberghi E, Ottoni E, et al (2011) Stone tool use by adult wild bearded capuchin monkeys (Cebus libidinosus). Frequency, efficiency and tool selectivity. J Hum Evol 61:97-107 . doi: 10.1016/j.jhevol.2011.02.010

Sterling EJ (1994) Aye-Ayes: specialists on structurally defended resources. Folia Primatol 62:142-154 . doi: 10.1159/000156771

Vermeij GJ, Currey JD (1980) Geographical variation in the strength of Thaidid snail shells. Biol Bull 158:383-389 . doi: 10.2307/1540864

Visalberghi E, Addessi E, Truppa V, et al (2009) Selection of effective stone tools by wild bearded capuchin monkeys. Curr Biol 19:213-217 . doi: 10.1016/j.cub.2008.11.064 Visalberghi E, Fragaszy D (2013) The Etho-Cebus Project: stone-tool use by wild capuchin monkeys. In: Sanz C, Call J, Boesch C (eds) Tool Use in Animals: Cognition and Ecology. Cambridge University Press, Cambridge, pp 203-223

Visalberghi E, Haslam M, Spagnoletti N, et al (2013) Use of stone hammer tools and anvils by bearded capuchin monkeys over time and space: construction of an archeological record of tool use. J Archaeol Sci 40:3222-3232

Visalberghi E, Sabbatini G, Spagnoletti N, et al (2008) Physical properties of palm fruits processed with tools by wild bearded capuchins (Cebus libidinosus). Am J Primatol $70: 884-891$

Visalberghi E, Sirianni G, Fragaszy D, Boesch C (2015) Percussive tool use by Taï Western chimpanzees and Fazenda Boa Vista bearded capuchin monkeys: a comparison. Philos Trans R Soc B 370:20140351 . doi: 10.1098/rstb.2014.0351 
bioRxiv preprint doi: https://doi.org/10.1101/267542; this version posted February 19, 2018. The copyright holder for this preprint (which

was not certified by peer review) is the author/funder. All rights reserved. No reuse allowed without permission.

Whiten A, Schick K, Toth N (2009) The evolution and cultural transmission of percussive technology: integrating evidence from palaeoanthropology and primatology. J Hum

Evol 57:420-435 . doi: 10.1016/j.jhevol.2008.12.010 